\title{
Introduction to Statistics
}

\author{
Berlin Chen \\ Department of Computer Science \& Information Engineering \\ National Taiwan Normal University
}




\section{What is Statistics?}

- Statistics is the field of study concerned with the collection, analysis, and interpretation (making decisions on) of uncertain data

- E.g., the explanation of social or economic trends through the analysis of data

- Or, in more common usage, statistics refers to numerical facts of the data

- E.g., the age of a student, the allowance of a student, the height of a student, etc.

- Another definition: Statistics is the science of conducting studies to collect, organize, summarize, analyze, and draw conclusions from data

統計學：“以偏概全” + “有所本”?? 


\section{Information Hierarchy}

- Data

- The raw material of information

- Information

- Data organized and presented by someone

- Knowledge

- Information read, heard or seen and understood

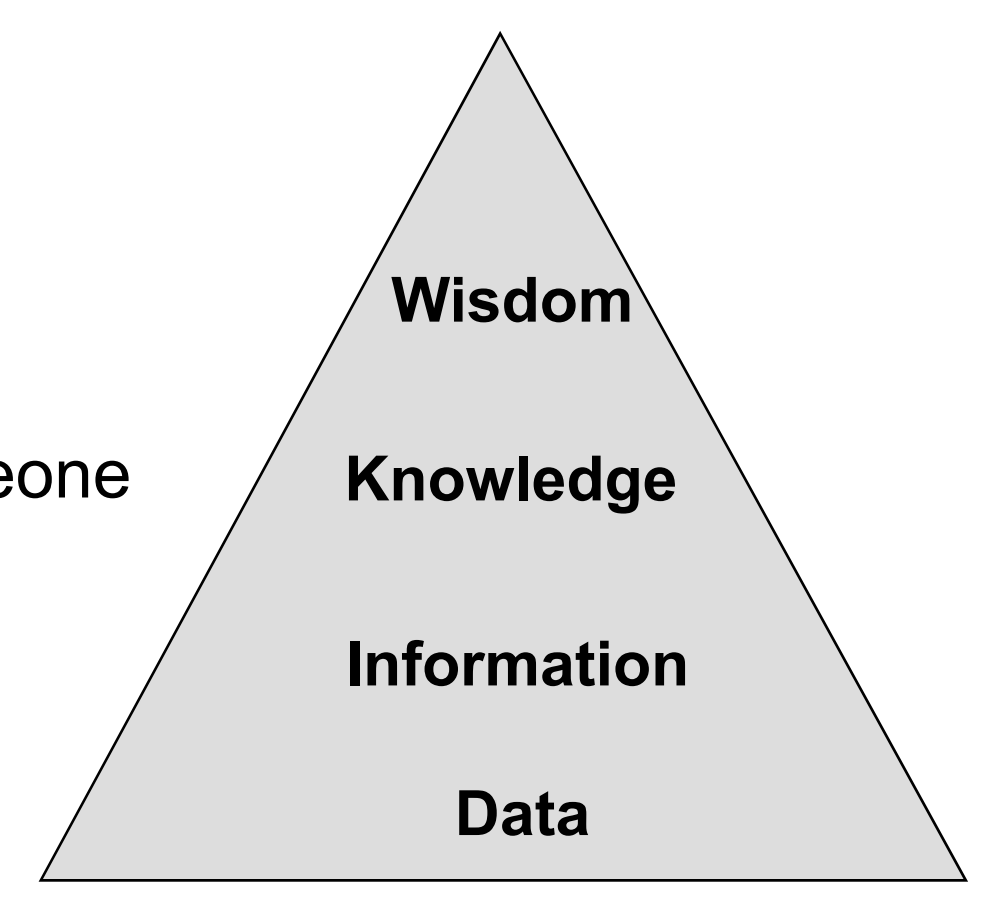

- Wisdom

- Distilled and integrated knowledge and understanding 


\section{Types of Statistics (1/4)}

- Broadly speaking, statistics can be divided into two areas

- Descriptive statistics (敘述統計學)

- Inferential statistics (推論統計學)

- Descriptive Statistics

- To be concerned with the methods of collecting data and of summarizing clearly the basic information they contain

- Collecting data refers to sampling, i.e., choosing a subset of data (a sample)

- Summarizing data refers to organizing, displaying, and describing data by tables, graphs, and summary measures

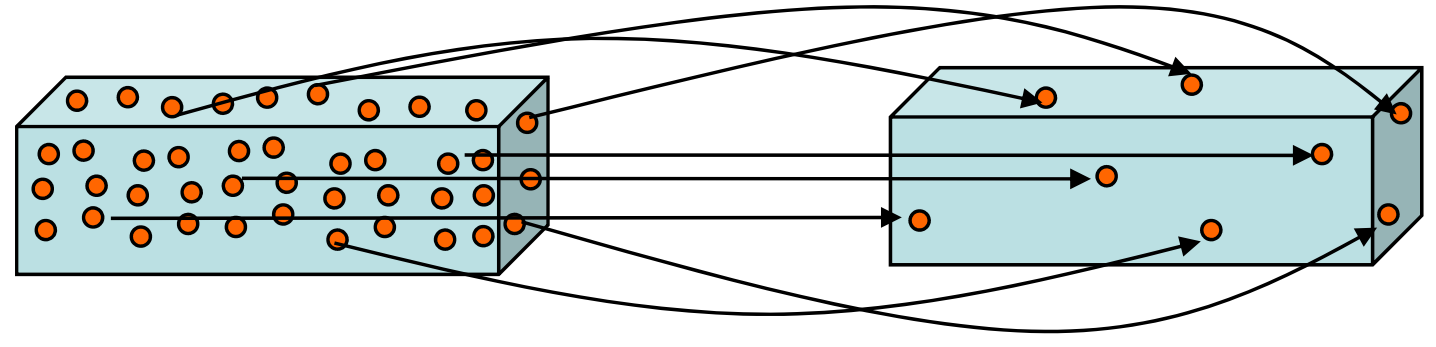




\section{Types of Statistics (2/4)}

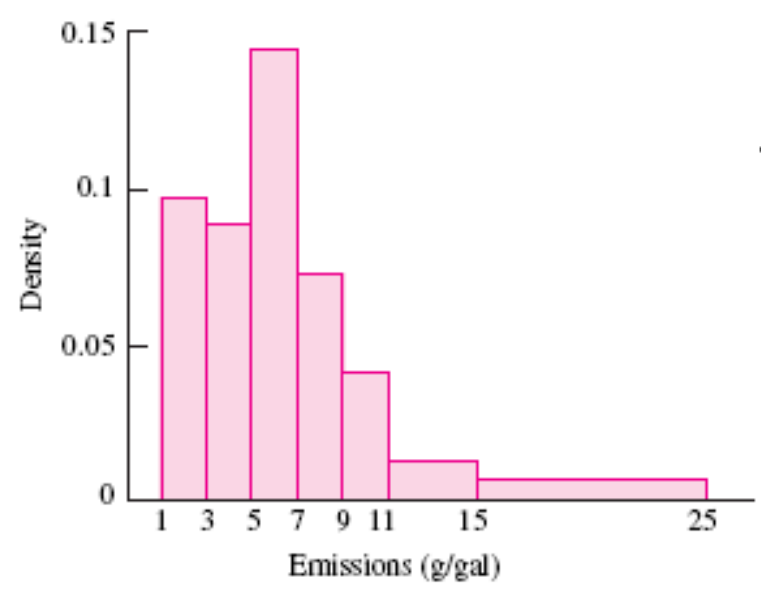

\begin{tabular}{cccc}
$\begin{array}{c}\text { Class } \\
\text { Interval }(g / g a l)\end{array}$ & Frequency & $\begin{array}{c}\text { Relative } \\
\text { Frequency }\end{array}$ & Density \\
\hline $1-<3$ & 12 & 0.193 & 0.0965 \\
$3-<5$ & 11 & 0.178 & 0.0890 \\
$5-<7$ & 18 & 0.290 & 0.1450 \\
$7-<9$ & 9 & 0.146 & 0.0730 \\
$9-<11$ & 5 & 0.082 & 0.0410 \\
$11-<15$ & 3 & 0.048 & 0.0120 \\
$15-<25$ & 4 & 0.063 & 0.0063
\end{tabular}

- Histogram and Frequency table for PM emissions of 62 vehicles driven at high altitude

- Inferential statistics

- Concerned with the methods that use sample results to help make decisions or predictions about the data (population)

- Or, the methods that draw conclusions from the data 


\section{Types of Statistics (3/4)}

- Example 1

- A machine makes 1000 steel rods per hour, with a specification of 0.45 $\pm 0.02 \mathrm{~cm}$

- An engineer would like determine the quality/quantity of the production process by randomly draw a sample of rods (say, 50 rods)

- Given that $92 \%$ of the sample meet the specification

- How likely is the size of difference between the sample proportion and the population proportion?

Standard derivation (Chapters 2 and 4 )

- How is he confident that the true population proportion will be in $92 \% \pm x \%$

Confidence interval (Chapter 5)

- Can he draw a conclusion that the percentage of good rods is at least $90 \%$

Hypothesis testing (Chapter 6) 


\section{Types of Statistics (4/4)}

- Example 2: relationship between two factors/populations

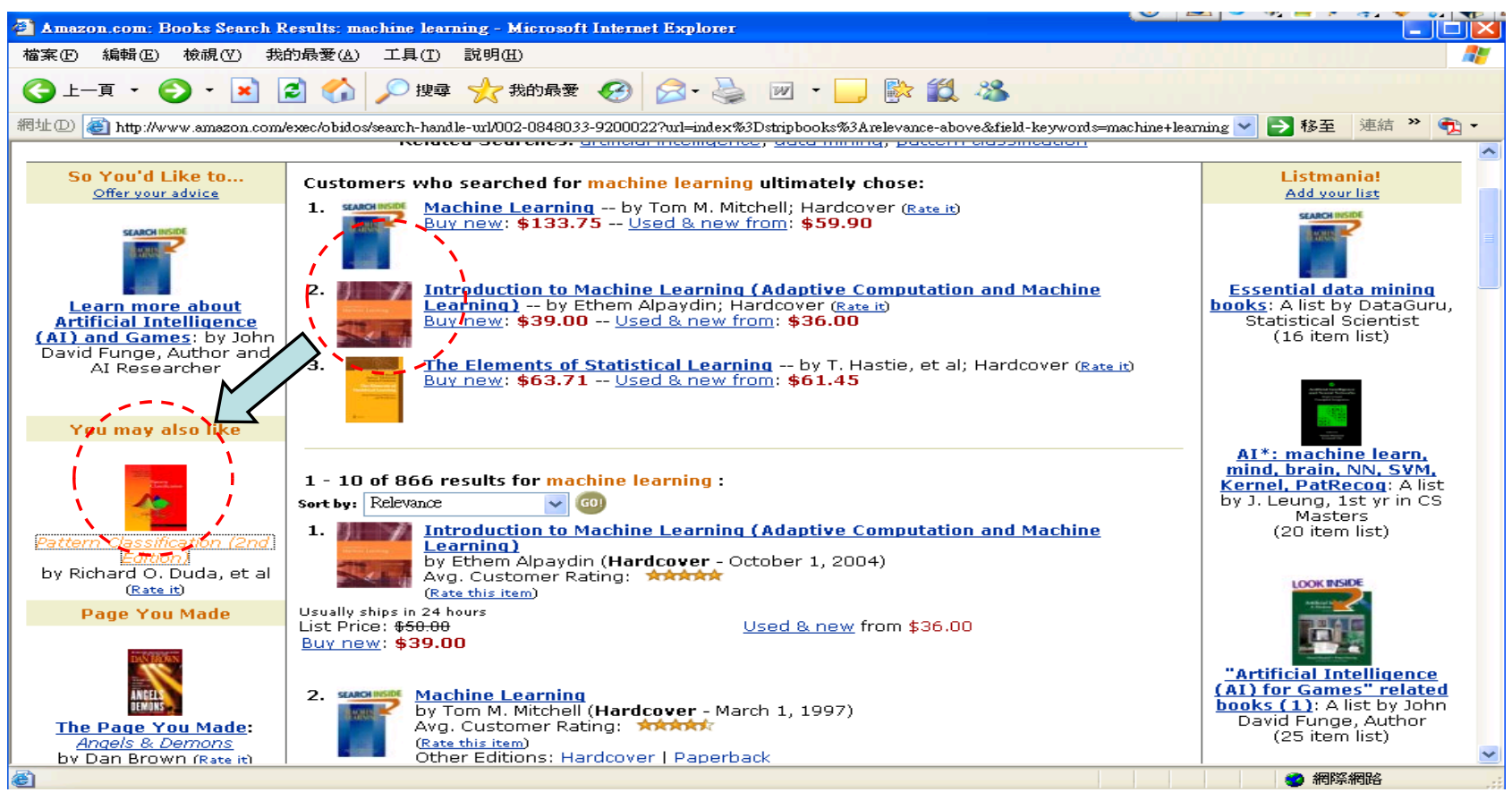

- Association Rule:

P( buying "Pattern Classification"| buying "Machine Learning" ) = ? 


\section{Popular Software Packages for Statistics}

- SPSS

- SAS

- MINITAB

- Microsoft Excel 


\section{Textbook and Reference}

- Textbook

- William C. Navidi, "Statistics for Engineers and Scientists," McGraw-Hill (2 edition, 2007)

- References

- Prem S. Mann, "Introductory Statistics," Wesley, (6 edition, 2007)

- D. P. Bertsekas, J. N. Tsitsiklis, "Introduction to Probability," Athena Scientific (2002) 


\section{Topics to be Covered}

- Descriptive Statistics (Chapter 1)

- Probability and Common Used Distributions (Chapters 2 \& 4, quick review)

- Propagation of Error (Chapter 3)

- Confidence Intervals (Chapter 5)

- Hypothesis Testing (Chapter 6)

- Correlation and Simple Linear Regression (Chapter 7)

- More Topics:

- Data Analysis and Dimension Reduction

- Data Cleansing and Presentation

- Bayesian Decision Theory

- Parametric Methods - Bias and Variance of the Estimator

$-\ldots$ 


\section{Grading (Tentatively)}

- Midterm and Final: $50 \%$

- Homework: 35\%

- Attendance/Other: $15 \%$

- TA: 劉家妏 同學 (碩二)

- E-mail: mkacat103@gmail.com

- Tel: (02)7734-6676 (資工系208室) 